\title{
A MODEL RELATING CEO SOCIAL INTELLIGENCE AND STRATEGIC ENGAGEMENT: A STUDY IN SMALL BUSINESS ORGANIZATIONS
}

\author{
M. Afzalur Rahim \\ Western Kentucky University • Bowling Green KY \\ Jeffrey P. Katz \\ Western Kentucky University • Bowling Green KY \\ Shane Spiller \\ Western Kentucky University • Bowling Green KY
}

\section{ABSTRACT}

Answering the call for additional investigation into microfoundations recently raised by organizational theorists and researchers, this study empirically investigates the relationship between social intelligence (SI) and strategic engagement (SE) among U.S. small business chief executive officers (CEOs). SI is being aware of key social contexts, effectively addressing challenges occurring in those contexts, understanding the concerns of others and their related personal situations/emotional states, and building/maintaining positive relationships in social situations thereby behaving appropriately. SE refers to actively participating in the process of formulation, implementation, and review of strategies for the purpose of improving the competitive position of the organization. Opinions of observers (top managers) regarding their respective CEOs' SI and SE were assessed with questionnaires to explore the relationship between SI and SE. Data analysis using LISREL 9.2 suggests that social intelligence is positively associated with strategic engagement behaviors among successful top executives. Implications for the selection of new CEOs and the training of existing CEOs are offered.

Keywords: Social intelligence, Leadership, Strategic engagement, Top management teams, CEO.

\section{INTRODUCTION}

Recent work by organizational theorists has concluded that organizational analysis should be concerned with how individual factors can be studied, and perhaps aggregated, to better understand the success of organizations at the collective level (Gavetti, 2012). The overall conclusion is the assertion that management and strategy researchers should seek to better understand the links between micro-macro strategy relationships (Barney \& Felin, 2013; Gavetti, 
2005). They suggest that microfoundations have been generally neglected in the literature of strategic management.

One of the encouraging signs in connection with this notion is that scholars are realizing that "we need to build microfoundations rooted in individual action and interaction" (Felin \& Foss, 2009, p. 162; see also Hodgson, 2012; Nadkarni $\&$ Herrmann, 2010). The editors of a special issue of Strategic Management Journal on psychological foundations of strategic management suggested that "strategic management theory lacks adequate psychological groundings . . . until strategy theory builds stronger foundations in psychology, it will struggle to explain the facts of firm performance" (Powell, Lovallo, \& Fox, 2011, p. 1370). In other words, individual organizational members have different ways of thinking, feeling, and behaving that can significantly influence strategic issues. According to Klein, Tosi, and Cannella (1999) "multi-level theories may illuminate the steps organizational actors may take, individually and collectively, to yield organizational benefits" (p. 243).

Over the past 10 years this discussion has resulted in studies reporting that psychological attributes of CEOs significantly influence the strategic orientation of the firm (Hiller \& Hambrick, 2005; Nadkarni \& Narayanan, 2007). A recent study by Nadkarni and Herrmann (2010) reports that strategic flexibility mediates the relationship between CEO personality and firm performance.

In this article, we take the lead from these findings and design a study to explore the relationship between CEOs' social intelligence and their strategic engagement of the firm. Social intelligence is one of the constructs that was not only neglected in the strategic management literature, but also in the literature of organizational behavior and management (Rahim, 2018, 2014; Rahim, Civelek, \& Liang, 2018).

The present study presents a structural equations model and provides empirical evidence that the SI competence of CEO's can significantly influence their contributions to strategic engagement. This study was designed to make a value-added contribution to the microfoundations of strategic management literature by showing the link between CEOs' social intelligence and their strategic engagement, that is, their active participation in the strategic engagement processes of the firm.

Humankind generally associates intelligence with cognitive, academic, or mathematical-logical competence. Scholastic Aptitude Tests, GPA, ACT, GMAT, GRE, and other admission tests are surrogates of cognitive intelligence. Although academic institutions offer programs that are associated with this 
intelligence, the relevant literature on management generally acknowledges the inadequacy of cognitive intelligence as a predictor of one's success in life or effective leadership (see the meta-analysis by Judge, Colbert, \& Ilies, 2004). That is, the management literature generally has ignored the contribution of other types of intelligence that are necessary for successful leadership at the top management level.

Gardner (1983), Goleman (2005), Mayer, Salovey, and Caruso (2008), Sternberg (1985), and Ang, Van Dyne, Koh, Ng, Templer, and Tay (2007) suggest that there are other components of intelligence-emotional, social, and cultural-that may influence one's success in life or business. People with these types of intelligence are described by scholars as having "street smarts"which indicate that an individual is not constrained simply because he or she may have below average academic intelligence or IQ (e.g. Bass, 2002; Rahim, Civelek, \& Liang, 2016). The value-added contribution of the present study is the successful evaluation of a micro-macro model specifying the relationships between SI components and the CEO's engagement with the strategic functions of the firm.

\section{STRATEGIC ENGAGEMENT}

Intelligence is associated with one's ability to interact effectively with the internal and external environments to be successful in life or as a leader in organizations. However, most published discussions regarding leadership and strategic engagement are focused at the national level rather than at the firmlevel. For example, Wright (2010) suggests that the concept of engagement "is an amorphous and vague ... Its purpose, parameters, and promise remain unclear" (p. 35). However, it seems that Wright's comment on the concept of engagement in the area of international politics is also applicable to a significant extent on the strategic engagement construct in organizations. Unfortunately, there is no consensus on the meaning of this construct in the area of management and organizational behavior. In the private sector, some management consultants have suggested that strategic engagement involves achieving changes in organizational culture and structure designed to improve performance (e.g., Guttman \& Hawkes, 2004; Smythe, 2007).

Others advocate employee engagement which emphasizes enhancing employees' commitment and loyalty to work for improving overall performance (Federman, 2009; Macey, Schneider, Barbara, \& Young, 2009). There are many websites that advocate various types of change for improving performance. 
Unfortunately, there is no evidence that these changes improved learning and effectiveness in organizations.

Thus, strategic engagement is associated with a top manager's active involvement in the strategy formulation, implementation, and review of processes to attain the goals of an organization. This involves changes in the process and structure at the macro-level so that top managers are actively involved in the continuous review and refinement of strategies for improving the competitive position of an organization. For the purpose of this study, CEO strategic engagement includes articulating a compelling vision, formulating, implementing and refining strategies, and moving those key factors from the drawing board to desirable organizational outcomes. Drawing from previous research and recommendations in the strategic management literature (Gavetti, 2012; Guttman \& Hawkes, 2004; Wright, 2010), strategic engagement is the process used by the leader of the firm to facilitate the interaction between the external environment of the firm, the key stakeholders of the firm, and the internal activities that align the goals of the firm with the expenditures of resources (Baron \& Markham, 2000).

\section{SOCIAL INTELLIGENCE}

Sternberg (2009) provides evidence that there are three types of intelligencecreative, analytical, and practical-that are needed for one's success. His concept of practical intelligence is very similar to the commonly-used notion of social intelligence. Several scholars suggest similar concepts-intrapersonal or emotional and interpersonal or social intelligence (Gardner, 1999; Goleman, 2005; Mayer, Salovey, $\&$ Caruso, 2008). Finally, cultural intelligence is another type of "intelligence" that has been suggested by Ang et al. (2007).

It is generally agreed that SI is different from cognitive intelligence. Although there is no agreement on the definition of the construct, many conclude that SI is associated with understanding the thinking, feelings and behaviors of others, interacting with them properly, and acting effectively in various situations (Ford \& Tisak, 1983; Kihlstrom \& Cantor, 2000; Sternberg, 2002). Thus, social intelligence is defined as being aware of relevant social situational contexts, effectively addressing challenges, understanding the concerns, feelings and emotional states of others, communicating by knowing what to say, when to say it and how to say it, and building and maintaining positive relationships with others (Rahim, 2014). This definition consists of four categories of abilities - situational awareness, situational response, cognitive empathy, and social skills. Situational awareness is associated with one's ability to collect data 
and information for the diagnosis and formulation of problem(s). Whereas situational response is associated with one's ability to use this information to make effective decisions to attain desired results. These two basic abilities, or competencies, are needed for one's success in life or effective leadership (Rahim, Civelek, \& Liang, 2015a, 2015b).

Cognitive empathy and social skills are needed to better understand the feelings and needs of people, communicate with them effectively, and build and maintain relationships. These two abilities can help CEOs remain aware of various social situational contexts, which in turn, help them improve their situational response competence. It is possible that these two abilities mediate or moderate the relationship between situational awareness and situational response. The theoretical basis of the four-category nomenclature of the SI construct is described as follows.

\section{Situational Awareness}

Bennis and Thomas (2002) have categorized this ability as contextual intelligence. This is associated with one's competence or ability to comprehend or assess relevant social situational contexts. CEOs must be very strong in this ability, as it is needed to collect relevant information from the internal and external environments and make an appropriate diagnosis of the firm's strengths, opportunities, weaknesses, and threats in a timely manner. This ability enables CEOs to formulate a problem correctly. If they feel that they do not have adequate information on a problem or a potential business opportunity, they are likely to engage in environmental scanning behavior. If they do not understand a particular situation involving a technical problem, they may seek help from experts so that they have an overall understanding of the problem. For example, experts may bring different and even contradictory assessments of a problem, but it is the CEO who decides which problem formulation reflects social reality and is to be accepted. One can infer that CEOs who have high situational awareness ability are better able to formulate their organization's problems or challenges correctly. A study by O'Brien and O'Hare (2007) reported that participants in training programs who had higher situational awareness performed well irrespective of the training conditions.

Situational awareness competence is important at all levels of management, but it is particularly important at the top management level. If a problem is wrongly formulated, one would follow a wrong solution to the problem. This would lead to Type III error, which is defined as the probability of solving the wrong problem when one should be solving the right problem (Mitroff, 1998; Mitroff \& Silvers, 
2010). CEOs who possess this ability are able to collect necessary information and formulate a problem correctly, thereby avoiding Type III errors. Situational awareness competence has been generally neglected in the theories of leadership, which implicitly assume that leaders can effectively diagnose the relevant situational variables and are able to formulate their problems correctly. However, leaders who are deficient on this competence may not be able to fully comprehend important situational issues.

\section{Situational Response}

This micro-factor is associated with one's competence or ability to deal with any social situation effectively. This is essentially the decision making competence of leaders that is positively influenced by their prior problem formulation. Although Bennis and Thomas (2002) describe this as adaptive capacity, situational response is a broader concept than that. In the present study, a distinction is made between the two abilities - situational awareness and situational response. It is possible for leaders to recognize or diagnose a situation or problem correctly, but they may not be able to make a decision due to political and other reasons that is likely to lead to desirable outcomes.

In the present study, an attempt was made to integrate the diverse literatures relating to the fields of organizational behavior and strategic management for the application of social intelligence. In connection with organizational learning, Argyris and Schon (1996) carefully examine the detection and correction of error involved in organizational learning. In connection with the management or organizational conflict, Rahim and Bonoma (1979) present a model of diagnosis of and intervention in conflict, and Schmidt and Tannenbaum (1960) describe these as abilities as "to diagnose an issue and its causes" and "to decide on the best course of action" (p. 107). The two processes, diagnosis or detection of error and intervention or correction of error, correspond well with the two components of SI-assessment of and responses to situational contexts. These two components are conceptually independent. Thus, it is possible for a leader to have high or low abilities associated with these two components. A high-high leader is more effective than a high-low, low-high, or low-low leader. In other words, these two abilities are essential for effective leadership.

The literature on leadership has generally done a better job of prescribing how to match leadership styles with situational variables for improving job performance and satisfaction of followers. Unfortunately, scholars have been unable to capture 
the unique situations for which creative responses (leadership styles) would be needed for improving outcomes. Contingency theories of leadership generally suggest that certain situational variables should be adequately matched with appropriate leadership styles in order to enhance job performance and satisfaction of subordinates. Unfortunately, leadership theories did not discuss the need for leaders to possess situational awareness and response competencies to define the situational variables and respond to them with appropriate styles. Even if a leader can diagnose a situation correctly, he or she may not possess the competence needed to make an effective decision to deal with it.

The preceding discussion made clear that situational awareness and situational response are two essential abilities that are needed for effective leadership. However, there are other abilities, such as cognitive empathy and social skills that can help leaders to improve their effectiveness. The following is a discussion of each ability as measurable variables.

\section{Cognitive Empathy}

Another component of SI that has been discussed by scholars is empathy (e.g. Goleman, 2005; Albrecht, 2007; see also Ang \& Goh, 2010). Empathy refers to understanding others and taking active interest in them, recognizing and responding to changes in their emotional states, and understanding their feelings. Several components of empathy are cognitive, intellectual, affective, and behavioral. Cognitive empathy is associated with one's ability to recognize the thinking, feelings, intentions, moods, and impulses of people inside and outside the organization and is a component of SI. Kaukiainen et al. (1999) suggest that "the cognitive component of empathy forms an essential part of social intelligence" (p. 83).

Cognitive empathy should help to improve a leader's awareness of the feelings and needs of supervisors, subordinates, and coworkers as well as people from outside the organization. This ability to connect with people should help to improve a leader's social skills. In other words, cognitive empathy should be positively associated with social skills. 


\section{Social Skills}

Most of the definitions of social intelligence include social skills which are one's ability or competence to speak in a clear and convincing manner that involves knowing what to say, when to say it, and how to say it. Social skills also involve building and maintaining positive relationships, acting properly in human relations, dealing with problems without demeaning those who work with him or her, and negotiating and managing conflict with tact and diplomacy.

Social skills competence enables a CEO to continuously collect relevant information from internal and external environments, which enhance their situational awareness. Social skills help leaders explain and justify their decisions to followers and motivate them so that the leaders' decisions are effectively implemented. Studies by Baron and Markham (2000) and Baron and Tang (2009) suggest that entrepreneurs' social skills-specific competencies that help them to interact effectively with others - may also play a role in their success.

In the previous section, it was argued that cognitive empathy directly influences social skills but indirectly influences situational awareness. Therefore, it is likely that social skills will mediate the relationship between cognitive empathy and situational awareness (Baron \& Kenny, 1986). As previously discussed, situational awareness positively influences situational response, but social skills indirectly influence situational response. Thus, it is likely that situational awareness will mediate the social skills-situational response relationship. On the basis of this literature review, the we present the following research hypotheses.

Hypothesis 1: Social skills will mediate the relationship between cognitive empathy and situational awareness.

Hypothesis 2: Situational awareness will mediate the relationship between social skills and situational response.

Hypothesis 3: Situational response will mediate the relationship between situational awareness and strategic engagement.

The hypotheses investigated in the present study are presented in the model identified in Figure 1. The solid lines indicate significant positive relationships. Dotted lines indicate indirect and non-significant relationships. 


\section{Figure 1}

\section{A Model of CEOs' Social Intelligence and Strategic Engagement}

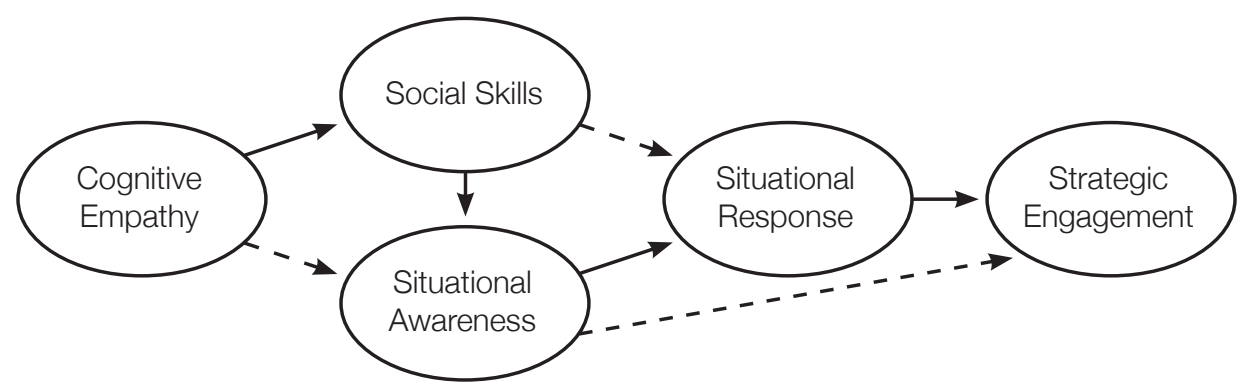

METHOD

\section{Sample and Procedure}

Four hundred members of the chamber of commerce in a southern state in the U.S. were invited to participate in the study. After two reminders 150 usable responses were received, i.e. a response rate of about 37.5 percent. As respondents were asked to estimate their CEOs' social intelligence and strategic engagement, a decision was made that each respondent must have at least five years of work experience with his/her CEO. As a result, 74 respondents were selected and their responses were used for further analysis. Chronological age and working experience with the present $\mathrm{CEO}$ were $46.48(\mathrm{SD}=10.15)$ and $13.42(\mathrm{SD}=$ 7.79) years, respectively. Their total job experience was 23.43 years $(\mathrm{SD}=9.74)$. Forty-eight percent of the respondents were female. Table 1 reports the relevant demographical statistics. 
Table 1

\section{Demographical Information of Respondents}

\begin{tabular}{lcc}
\hline Item & Mean & SD \\
\hline Age & 46.48 & 10.15 \\
Education & 14.59 & 2.19 \\
Experience & 23.43 & 9.74 \\
Exp. w/CEO & 13.42 & 7.79 \\
CEO's educ. & 15.30 & 2.69 \\
Employees & 132.29 & 121.64 \\
Gender & $52 \%$ male & $48 \%$ female \\
\hline
\end{tabular}

\section{MEASUREMENT}

\section{Social Intelligence}

The four components of CEOs' SI were measured with 28 items adapted from a new instrument—Rahim Social Intelligence Test (RSIT) — developed by Rahim (2014). The items adapted from the RSIT were designed to measure observers' (top managers) perceptions of their respective CEOs' SI. The RSIT was designed on the basis of repeated feedback from respondents and faculty and an iterative process of exploratory factor analyses of various sets of items in multiple samples. The final set of items was selected on the basis of a confirmatory factor analysis.

The RSIT uses a 5-point Likert scale (5 = Strongly Agree . . . 1 = Strongly Disagree) for ranking each of the items, and a higher score indicates a greater SI of a CEO. The subscales were created by averaging responses to their respective items. Sample items are: "The CEO of our company can size up a situation, he/ she finds himself/herself in, rather quickly" (Situational awareness); "The CEO of our company usually adapts appropriately to different situations" (Situational response); "The CEO of our company understands people's feelings transmitted through nonverbal messages" (Cognitive empathy); and "The CEO of our company interacts appropriately with a variety of people" (Social skills). Rahim (2014) provided evidence of internal consistency and indicator reliabilities and convergent, discriminant, and criterion validities of the instrument and that it was free from social desirability response bias. 


\section{Strategic Engagement}

This was measured with nine items particularly designed for this study. The instrument uses a 5-point Likert scale ( 5 = Strongly Agree . . 1 = Strongly Disagree $)$ for ranking each item and a higher score indicates greater SE of a CEO. These items were completed by the CEO's direct subordinates of the firm and directly assess the CEO's level of strategic engagement. Sample items for this scale are, my supervisor (the CEO): "...participates in the strategy formulation process" and "participates in strategy implementation." The items were factor analyzed to determine they form a single index measuring the level of CEO strategic engagement as observed by the CEO's closest direct-reporting employees.

\section{ANALYSIS AND RESULTS}

The first part of the analysis was designed to test the psychometric properties of the measures of SI and SE. The second part of the analysis was designed to test the three study hypotheses. Data analyses were performed with SPSS 24 and LISREL 9.2 (Jöreskog \& Sörbom, 1996a, 1996b) statistical packages.

\section{Validity Assessment (Measurement Model)}

Confirmatory factor analysis of the 28 SI and nine SE items was computed. Results show excellent fit indexes for the five components of the two instruments (see Table 2).

Table 2

Fit Indexes for the Measurement and Structural Equations Models

\begin{tabular}{lcc}
\hline Fit Index & $\begin{array}{c}\text { Measurement } \\
\text { Model }\end{array}$ & $\begin{array}{c}\text { Structural } \\
\text { Equations Model }\end{array}$ \\
\hline X2/df & 1.00 & 1.04 \\
RMSEA & .00 & .00 \\
RMSR & .06 & .07 \\
NFI & .97 & .95 \\
CFI & 1.00 & 1.00 \\
IFI & 1.00 & 1.00
\end{tabular}

Note: $R M S E A=$ Root Mean Square Error of Approximation, $R M S R=$ Root Mean Square Residual, NFI = Normed Fit Index, CFI = Comparative Fit Index, and IFI = Incremental Fit Index 
The values for the $\chi^{2} / \mathrm{df}$ should be less than 4, Root Mean Square Error of Approximation (RMSEA) and Root Mean Square Residual (RMSR) should be low and generally $\leq .07$. The values for other fit indexes, such as Normed Fit Index, Comparative Fit Index, Incremental Fit Index, and Goodness of Fit Index should be $\geq .90$. The fit indexes for the measurement model satisfied these requirements $\left(\chi^{2} / \mathrm{df}=1.00, \mathrm{RMSEA}=.00, \mathrm{RMSR}=.06, \mathrm{NFI}=.97, \mathrm{CFI}=1.00\right.$, and $\left.\mathrm{IFI}=1.00\right)$. Overall, these indexes indicate that the RSIT is a 4-dimensional measure of social intelligence and the criterion measure is a one-dimensional measure of SE.

The two questionnaires were completed by the same subjects at the same time, which could lead to common method variance. The extent of common method variance present in the measures was tested with one of the procedures suggested by Podsakoff, MacKenzie, Lee, and Podsakoff (2003). If common method variance was present, then all the observed variables (items) measuring SI and SE will load on a single factor. If a single-factor solution fits the data well, one can conclude that common method variance is mainly responsible for explaining the relationships among the variables (Mossholder, Bennett, Kemery, \& Wesolowski, 1998). A onefactor measurement model was computed and the results show that all the six fit indexes $\left(\chi^{2} / \mathrm{df}=6.43\right.$, RMSEA $=21, \mathrm{RMSR}=.13$, NFI $=.80, \mathrm{CFI}=.86$, and $\mathrm{IFI}=$ .78) were unsatisfactory. In other words, the single-factor model did not fit the data and, as a result, the absence of five components of the two measures or the presence of common method variance in the measures should not be assumed.

\section{Convergent Validity}

The average variance extracted by all the observed variables loading on a given factor measures convergent validity and should exceed .50 (Carr, 2002). In the present study, these values were averaged for factors and all of the average $R^{2}$ exceeded .50 , the threshold for supporting convergent validity.

This validity for the five latent variables (situational awareness, situational response, cognitive empathy, social skills, and strategic engagement) was judged by examining whether each observed variable had a statistically significant factor loading on its specified factor (Netemeyer, Johnston, \& Burton, 1990). Factor loadings were highly significant, with a minimum $t$-ratio of $4.04(p<.01)$. These results provided support for the convergent validity of the latent variables. 


\section{Discriminant Validity}

One of the tests for discriminant validity requires squared correlations between factors to be less than the average variance extracted for each factor (Carr, 2002). Results provide support for the discriminant validity between SI and SE.

Another test for discriminant validity involves pair-wise comparisons of latent variables using a Chi-square difference test (Anderson \& Gerbing, 1988). For each pair of latent variables two models are developed. In one model the two latent variables are defined by their respective observed variables. In the second model, the correlation between the latent variables is constrained to 1.00. The Chisquare difference test can be used to determine if the appropriately defined twofactor model provides statistically better fit than the constrained model. In each pairwise comparison of latent variables, the constrained model resulted in a significantly higher $\chi^{2}$ value supporting discriminant validity. Overall, there is adequate support for discriminant validity.

\section{Univariate Normality}

The samples exhibited a high degree of univariate normality with skewness and kurtosis statistics well within the acceptable levels of 1 and 7 for all items.

\section{Descriptive Statistics and Reliability Coefficients}

Table 3 reports the means, standard deviations, indicator and Cronbach $\alpha$ internal consistency reliabilities, and inter-correlations of the five variables. The inter-correlations of the five variables ranged between .42 and .68 . All the correlations were positive and significant at .001 level. The variance inflation factor (VIF), which ranged 2.10 and 2.55 was $<10.00$ which indicate that multicollinearity was not a problem. 
Table 3

Means, Standard Deviations, Cronbach $\alpha$ and Indicator

Reliabilities, Correlations, and Variance Inflation Factor

\begin{tabular}{lccccccccc}
\hline Variable & $\mathbf{M}$ & SD & $\mathbf{a}$ & $\mathbf{I R}$ & $\mathbf{1}$ & $\mathbf{2}$ & $\mathbf{3}$ & $\mathbf{4}$ & $\mathbf{V I F}$ \\
\hline $\begin{array}{l}\text { 1. Situational } \\
\text { awareness }\end{array}$ & 3.84 & .84 & .77 & .50 & & & & & 2.10 \\
$\begin{array}{l}\text { 2. Situational } \\
\text { response }\end{array}$ & 3.96 & .66 & .72 & .54 & .67 & & & & 2.50 \\
$\begin{array}{l}\text { 3. Cognitive } \\
\text { empathy }\end{array}$ & 3.48 & .75 & .86 & .60 & .65 & .66 & & & 2.55 \\
$\begin{array}{l}\text { 4. Social skills } \\
\begin{array}{l}\text { 5. Strategic } \\
\text { engagement }\end{array}\end{array}$ & 3.99 & .71 & .81 & .62 & .54 & .68 & .43 & & 2.34 \\
\hline
\end{tabular}

Note. $N=75 . I R=$ Indicator reliability, $V I F=$ Variance inflation factor. All the correlations are significant at $p<.001$ (two-tailed).

\section{Indicator Reliability}

Each item has a reported $R^{2}$ that measures the item's variance explained by the factor. This measure of indicator reliability should be greater than or equal to .50 for each of the indicators. The $R^{2} s$ for all the variables ranged between .50 and .69 . These reliabilities were judged sufficient.

\section{Internal Consistency Reliability}

The internal consistency reliability coefficients of the five scales/subscales, as assessed with Cronbach $\alpha$, ranged between .72 and .93. Overall, these coefficients are satisfactory.

\section{Structural Equations Model}

The three mediation models presented in Figure 1 were tested with a SEM suggested by James and Brett (1984) that differs from the widely used incremental approach of Baron and Kenny (1986). In the SEM, mediation is indicated when the paths between the independent and mediator, and the path between the mediator variable and the outcome variable are significant and the overall model shows acceptable goodness of fit (see James, Mulaik, \& Brett, 2006 for details). The fit indices, which are portrayed in Table 2 suggest an excellent fit for the hypothesized 
$\operatorname{model}\left(\chi^{2} / \mathrm{df}=1.04, \mathrm{RMSEA}=.00, \mathrm{RMSR}=.07, \mathrm{NFI}=.95, \mathrm{CFI}=1.00, \mathrm{IFI}=1.00\right)$. The path coefficients for the SEM are presented in Table 4.

\section{Table 4}

\section{Statistics for Structural Equations Model}

\begin{tabular}{lcc}
\hline Relationship & $\boldsymbol{\beta}$ & $\mathbf{t}$ \\
\hline $\mathrm{CE} \rightarrow \mathrm{SS}$ & .90 & $6.69^{\star \star \star}$ \\
$\mathrm{SS} \rightarrow \mathrm{SA}$ & .91 & $5.72^{\star \star \star}$ \\
$\mathrm{SA} \rightarrow \mathrm{SR}$ & .99 & $5.94^{\star \star \star}$ \\
$\mathrm{SR} \rightarrow \mathrm{SE}$ & .49 & $3.75^{\star \star}$ \\
\hline
\end{tabular}

$* * p<.01 . * * * p<.001$.

Note: $C E=$ Cognitive empathy, $S A=$ Situational awareness, $S S=$ Social skills, $S R=$ Situational response, $S E=$ Strategic engagement.

- Hypothesis 1 is concerned with the mediation effect of social skills on the relationship between cognitive empathy and situational awareness. The path from cognitive empathy to social skills $(\beta=.90, p<.001)$ and the path from social skills to situational awareness $(\beta=.91, p<.001)$ were significant which provide full support for Hypothesis 1 . This finding implies that cognitive empathy can influence situational awareness only indirectly through social skills. A mediation hypothesis suggests that the independent variable (i.e., cognitive empathy) causes the mediator variable (i.e., social skills), which in turn, causes the dependent variable (i.e., situational awareness). The mediator variable, then, serves to clarify the nature of the relationship between the independent and dependent variables.

- A similar procedure was used to test Hypothesis 2, which is concerned with the mediation effect of situational awareness on the relationship between social skills and situational response. The path from social skills to situational awareness $(\beta=.91, p<.001)$ and the path from situational awareness to situational response $(\beta=.99, p<.001)$ were significant which provide full support for Hypothesis 2 . This finding implies that social skills can influence situational response only indirectly through situational awareness. This mediation hypothesis suggests that the independent variable (i.e., social skills) influences the mediator variable (i.e., situational awareness), which in turn, influences the dependent variable (i.e., situational response).

- Hypothesis 3 is concerned with the mediation effect of situational response on the relationship between situational awareness and strategic engagement. The 
path coefficients from situational awareness to situational response $(\beta=.99, \mathrm{p}$ $<.001)$ and from situational response to strategic engagement $(\beta=.49, \mathrm{p}<.01)$ provided support for this hypothesis.

\section{$\overline{\text { DISCUSSION }}$}

This was an exploratory investigation to test a model of CEOs' leadership as measured by strategic engagement based on their social intelligence. Our results provide compelling support for the model presented in Figure 1. Previous studies did not test the relationships of top managers' perception of CEOs' SI components to each other and to SE. The present study contributes to our understanding of the microfoundational linkages between situational awareness and situational response and between situational response and strategic engagement. It also contributes to our understanding of the relationships between cognitive empathy, social skills, and situational awareness as they relate to situational response.

The results provide acceptable evidence of convergent and discriminant validities as well as internal consistency and indicator reliabilities of the measure of SI and SE. Evidence from the present study and the studies by Rahim (2014) and Rahim et al. (2015a) provided support for construct validity of the measure of SI. The present study provided some new evidence for the construct validity for $\mathrm{CEO}$ strategic engagement. However, since the measure of SE is relatively new, we recommend additional assessment of the SE instrument in other contexts, such as larger organizations and not-for-profit firms. In addition, it was assumed the SE respondents were the closest subordinate managers to the CEO with full knowledge of the CEO's activities. Future research should include hierarchy information regarding the relationship between the two.

\section{Implications for Management}

There are several key implications of our study. First, it is clear that cognitive empathy, social skills, situational awareness, and situational response are important for the success of top managers. Those social intelligence factors have direct and indirect impacts on the strategic engagement displayed by top organizational leaders. This study supports the contention that microfoundations are complex yet critical to better understanding the interaction between individual behaviors and the strategic focus of the firm (Klein, Tosi, \& Cannella, 1999). Clearly, behavioral interviews for top managers need to include assessments of the four components of SI along with the assessment of CEO strategic engagement. For those seeking higher level 
leadership roles within their own organizations, appropriate employee development plans may be needed to strengthen their SI competencies. Such activities may include additional education and role-playing training (Cherniss \& Adler, 2000; Goleman, 2005). Second, CEOs and managers should be encouraged to enhance their abilities through continuous self-learning and through mentorship programs. Organizations should provide positive reinforcements for learning and improving CEOs' essential SI competencies needed for their specific jobs.

Finally, even though education and training are useful for improving the SI of supervisors and leaders, there are limitations on enhancing the appropriate workplace behaviors in each of the SI components. To address this issue, the board of directors should clarify the position description of CEOs to specifically acknowledge the importance of SI factors and SE behaviors as necessary for job success.

\section{Strengths and Limitations}

One of the strengths of this study is that the measures of independent and dependent variables were collected from observers, which should reduce the problems of method variance (Podsakoff, MacKenzie, Lee, \& Podsakoff, 2003). Also, confirmatory factor analyses of the items indicated the absence of common method variance. If common method variance was present, the items of the independent and criterion measures will not significantly load on the five a priori factors.

Limitations of this field study should be noted. Data were collected from a convenience sample and might limit generalizability of the results. Also, a small sample size of 74 cases may be an issue that should be investigated in future studies.

\section{REFERENCES}

Albrecht, K. (2007). Social intelligence: The new science of success. San Francisco: Jossey-Bass.

Anderson, J. C., \& Gerbing, D. W. (1988). Structural equation modeling in practice:

A review and recommended two-step approach. Psychological Bulletin, 103, 411-423.

Ang, S., Van Dyne, L., Koh, C. K. S., Ng, K. Y., Templer, K. J., Tay, C. (2007). Cultural intelligence: Its measurement and effects on cultural judgment and decision making, cultural adaptation, and task performance. Management and Organization Review, 3, 335-371. 
Ang, R. P., \& Goh, D. H. (2010). Cyberbullying among adolescents: The role of affective and cognitive empathy, and gender. Child Psychiatry: Human Development, 41, 387-397.

Argyris, C., \& Schon, D. (1996). Organizational learning-II. Reading MA: AddisonWesley.

Barney, J., \& Felin, T. (2013). What are microfoundations? The Academy of Management Perspectives, 27, 138-155.

Baron, R. A., \& Markham, G. D. (2000). Beyond social capital: How social skills can enhance entrepreneurs' success. Academy of Management Executive, 14, 106-116.

Baron, R. A., \& Tang, J. (2009). Entrepreneurs' social skills and new venture performance: Mediating mechanisms and cultural generality. Journal of Management, 35, 282-306.

Baron, R. M., \& Kenny, D. A. (1986). The moderator-mediator variable distinction in social psychological research: Conceptual, strategic, and statistical considerations. Journal of Personality and Social Psychology, 51, 1173-1182.

Bass, B. M. (2002). Cognitive, social, and emotional intelligence. In R. E. Riggio, S. E. Murphy, \& F. J. Pirozzolo (Eds.), Multiple intelligences and leadership (pp. 105-118). Mahwah, NJ: Erlbaum.

Bennis, W. G., \& Thomas, R. J. (2002). Geeks and geezers. Cambridge, MA: Harvard Business School Press.

Carr, C. L. (2002). A psychometric evaluation of the expectations, perceptions, and difference-scores generated by the IS-Adapted SERVQUAL Instrument. Decision Sciences, 33, 281-296.

Cherniss, C., \& Adler, M. (2000). Promoting emotional intelligence in organizations: Making training in emotional intelligence effective. Alexandria, VA: ASTD Federman, B. (2009). Employee engagement: A roadmap for creating profits, optimizing performance, and increasing loyalty. San Francisco: Jossey-Bass.

Felin, T., \& Foss, N. J. (2009). Organizational routines and capabilities: Historical drift and a course-correction toward microfoundations. Scandinavian Journal of Management, 25, 157-167.

Ford, M. E., \& Tisak, M. S. (1983). A further search for social intelligence. Journal of Educational Psychology, 75, 197-206.

Gardner, H. (1983). Frames of mind: The theory of multiple intelligences. New York: Basic Books.

Gardner, H. (1999). Intelligence reframed. New York: Basic Books. 
Gavetti, G. (2005). Cognition and hierarchy: Rethinking the microfoundations of capabilities' development. Organization Science, 16, 599-617.

Gavetti, G. (2012). Toward a behavioral theory of strategy. Organization Science, $23,267-285$.

Goleman, D. (2005). Social intelligence: The new science of human relationships. New York: Bantum Books.

Guttman, H. M., \& Hawkes, R. S. (2004). New rules for strategic engagement. Journal of Business Strategy, 25, 34-38.

Hiller, N. J., \& Hambrick, D. C. (2005). Conceptualizing executive hubris: The role of (hyper-) core self-evaluations in strategic decision-making. Strategic Management Journal, 26, 297-319.

Hodgson, G. M. (2012). The mirage of microfoundations. Journal of Management Studies, 49, 1389-1394.

James, L. R., \& Brett, J. M. (1984). Mediators, moderators, and tests of for mediation. Journal of Applied Psychology, 69, 307-321.

James, L. R., Mulaik, S. A., \& Brett, J. M. (2006). A tale of two methods. Organizational Research Methods, 9, 233-244.

Jöreskog, K. G., \& Sörbom, D. (1996a). LISREL 8: User's reference guide. Chicago: Scientific Software International.

Jöreskog, K. G., \& Sörbom, D. (1996b). PRELIS 2: User's reference guide. Chicago: Scientific Software International.

Judge, T. A., Colbert, A. E., \& Ilies, R. (2004). Intelligence and leadership: A quantitative review and test of theoretical propositions. Journal of Applied Psychology, 89, 542-552.

Kaukiainen, A., Bjorkqvist, K., Lagerspetz, K., Osterman, K, Salmivalli, C., Rothberg, S., \& Ahlbom,A. (1999). The relationships between social intelligence, empathy, and three types of aggression. Aggressive Behavior, 25, 81-89.

Kihlstrom, J. F., \& Cantor, N. (2000). Social intelligence. In R. J. Sternberg (Ed.), Handbook of intelligence (2nd ed., pp. 359-379). Cambridge, UK: Cambridge University Press.

Klein, K., Tosi, H., \& Cannella, A. (1999). Multilevel theory building: Benefits, barriers, and new developments. Academy of Management Review, 24, 243-248.

Macey, W. H., Schneider, B., Barbara, K. M., \& Young, S. A. (2009). Employee engagement: Tools for analysis, practice, and competitive advantage. West Sussex, UK: Wiley-Blackwell.

Mayer, J. D., Salovey, P., \& Caruso, D. R. (2008). Emotional intelligence: New ability or eclectic traits? American Psychologist, 63, 503-517. 
Mitroff, I. I. (1998). Smart thinking for crazy times: The art of solving the right problems. San Francisco: Berrett-Koehler.

Mitroff, I. I., \& Silvers, A. (2010). Dirty rotten strategies: How we trick ourselves and others into solving the wrong problems precisely. Stanford, CA: Stanford University Press.

Mossholder, K. W., Bennett, N., Kemery, E. R., \& Wesolowski, M. A. (1998). Relationships between bases of power and work reactions: The meditational role of procedural justice. Journal of Management, 24, 533-552.

Nadkarni, S., \& Herrmann, P. (2010). CEO personality, strategic flexibility, and firm performance: The case of the Indian business process outsourcing industry. Academy of Management Journal, 53, 1050-1073.

Nadkarni S., Herrmann P., \& Pérez P. 2011. Domestic mindsets and early international performance: The moderating effect of global industry conditions, Strategic Management Journal, 32, 510531.

Nadkarni, S., \& Narayanan, V. K (2007). Strategic schemas, strategic flexibility, and firm performance: The moderating role of industry clock speed. Strategic Management Journal, 28, 243-270.

Netemeyer, R. G., Johnston, M. W., \& Burton, S. (1990). Analysis of role conflict and role ambiguity in a structural equations framework. Journal of Applied Psychology, 75, 148-157.

Nunnally, J. C. (1978). Psychometric theory (2nd ed.). New York: McGraw-Hill.

O'Brien, K. S., \& O'Hare, D. (2007). Situational awareness ability and cognitive skills training in a complex real-world task. Ergonomics, 50, 1064-1091.

Podsakoff, P. M., MacKenzie, S. B., Lee, J. Y., \& Podsakoff, N. P. (2003). Common method biases in behavioral research: A critical review of the literature and recommended remedies. Journal of Applied Psychology, 88, 879-903.

Powell, T. C., Lovallo, D., \& Fox, C. (2011). Behavioral strategy. Strategic Management Journal, 33, 1369-1386.

Rahim, M. A. (2014). A structural equations model of leaders' social intelligence and creative performance. Creativity and Innovation Management, 23 (1), 4456.

Rahim, M. A. (2018). A structural equations model of social intelligence and job performance, Applied Management Journal, 19, 92-108.

Rahim, M. A., \& Bonoma, T. V. (1979). Managing organizational conflict: A model for diagnosis and intervention. Psychological Reports, 44, 1323-1344. 
Rahim, M. A., Civelek, I., \& Liang, H. (2018). A process model of social intelligence and problem solving style for conflict management, International Journal of Conflict Management.

Rahim, M. A., Civelek, I., \& Liang, H. (2016). A model of leaders' social intelligence and followers' satisfaction with annual evaluation. Current Topics in Management, 18. 1-16.

Rahim, M. A., Civelek, I., \& Liang, H. (2015a). A model of department chairs' social intelligence and faculty members' turnover intention. Intelligence, 53, 65-71.

Rahim, M. A., Civelek, I., \& Liang, H. (2015b). Department chairs as leaders: A model of social intelligence and creative performance in a state university. Business Creativity \& the Creative Economy, 1 (1), 53-60.

Schmidt, W. H., \& Tannenbaum, R. (1990, November-December). Management of differences. Harvard Business Review, pp. 107-115.

Smythe, J. (2007). The CEO: Chief engagement officer: Turning hierarchy upside down to drive performance. Hampshire: UK: Grower.

Sternberg, R. J. (1985). The triarchic mind: A new theory of human intelligence. New York: Viking.

Sternberg, R. J. (2002). Successful intelligence: A new approach to leadership. In R. E. Riggio, S. E. Murphy, \& F. J. Pirozzolo (Eds.), Multiple intelligenecs and leadership (pp. 9-28). Mahwah, NJ: Erlbaum.

Sternberg, R. J. (2009, Fall). Wisdom, intelligence, and creativity synthesized: A new model for liberal education. Liberal Education, pp. 10-15.

Wright, T. (2010). Strategic engagement's track record. Washington Quarterly, 33 (3), 35-60.

\section{BRIEF BIOGRAPHICAL SKETCH OF AUTHORS}

M. Afzalur Rahim (Ph.D. University of Pittsburgh) is a University Distinguished Professor of Management at Western Kentucky University. He specializes in the management of organizational conflict, emotional and social intelligence, creativity, and organizational learning.

Jeff Katz (Ph.D. University of Florida) is the Oppitz Endowed Professor of Business and Professor of Management at Western Kentucky University. His research focuses on global competitors, strategic decision-making, and corporate governance.

Shane Spiller (Ph.D. University of Alabama) is a Professor of Management and Hays Watkins Teaching Fellow at Western Kentucky University. His research interests include decision-making, leadership, and ethics. 